\title{
La gratificante tarea de ser revisor
}

\section{The rewarding experience of being a peer reviewer}

Este fin de año nos despedimos de nuestro querido equipo editorial después de 4 años de trabajar en la revisión por pares. Se siente como si hubiera sido ayer aquella primera reunión porque, como dice la expresión popular, el tiempo pasa volando cuando uno se divierte.

En un mundo donde la información se encuentra en expansión constante, de forma tan exponencial que resulta casi agobiante, el objetivo de las revistas científicas es contribuir a la correcta difusión del conocimiento. Para ello, se debe canalizar y seleccionar toda información valiosa a fin de transmitirla de modo eficiente, práctico y confiable. Detrás de esta honorable tarea, se encuentra el equipo editorial.

De cara a despedirnos, hicimos una mirada retrospectiva y quisimos compartir nuestra experiencia para incentivar a los futuros revisores. No encontramos mejor manera que responder a la pregunta que, posiblemente, todos nos planteamos en los inicios: ¿̨por qué ser revisor?

El proceso de revisión es constructivo. Los comentarios generan una reestructuración del manuscrito que ayuda a una mejor comprensión del texto. Así, se contribuye a mantener altos los estándares de calidad de la literatura médica mundial. No olvidemos que Dermatología Argentina se encuentra indexada en motores de búsqueda que hacen posible su difusión internacional.

La revisión por pares es, sin duda, la herramienta más valiosa que tienen las revistas científicas para evaluar los artículos enviados. Esta tarea permite el intercambio de opiniones dentro de una atmósfera de colaboración y respeto con los demás revisores, que supone un gran crecimiento personal.

También faculta a acceder a información actualizada antes de su publicación. Cada trabajo evaluado implica una investigación detallada del tema y determina un proceso de educación médica continua.

Pertenecer a un equipo editorial nos ha enriquecido como autoras, ya que la mejor forma de responder a los comentarios de un revisor es "ponerse en su piel".

Somos conscientes de la responsabilidad y el honor que implica conformar un equipo editorial. Las nuevas generaciones tendrán en cuenta que, al cumplir con esta tarea, se han de apoyar en los hombros de gigantes de la Dermatología argentina que precedieron nuestro lugar.

Estamos seguras de que quienes nos reemplacen continuarán trabajando para mantener la excelencia y la difusión del conocimiento científico, a través de Dermatología Argentina, cuyo fin último es la mejoría de nuestros pacientes.

Para finalizar, nos despedimos y, en concordancia con lo expresado por la Dra. Carla Minaudo en su editorial "Legar o no legar", publicado en la edición no 4 de 2019 , esperamos haber podido dejar un pequeño legado en la historia de nuestra querida Revista.

Dra. María Eugenia Caram Dra. Paula Boggio

Dra. Lucrecia Infante Comité de Redacción 2017-2020 